DOI: http://doi.org/10.21698/simi.2018.fp11

\title{
PHOSPHATE REMOVAL FROM WASTEWATER BY USING LOW-COST ADSORBENT MATERIALS
}

\author{
Oanamari Daniela Orbulet, Cristina Modrogan, Cristina Orbeci, Dancila Madelene
}

University Politehnica of Bucharest, Faculty of Applied Chemistry and Materials Science, Analytical Chemistry and Environmental Engineering Department, 1-7 Polizu, Bucharest, c_modrogan@yahoo.com, Romania

\begin{abstract}
The need to develop new technologies for removing and recovering phosphates from wastewater has derived from increasing the demand for these sustainable compounds, setting stricter limits for discharges in order to prevent eutrophication of natural water resources, as well as tightening sludge disposal restrictions derived from wastewater plants. Removing phosphates from domestic and industrial wastewater and rationalizing the use of fertilizers in agriculture lead to reducing the main factors driving the proliferation of aquatic vegetation and hence, the secondary pollution of surface water. The subject of this work is part of an environmental issue and proposes a method for wastewater depollution by using adsorption processes, taking into account the technical and economic aspects, by using low-cost adsorbents namely pumice stone and autoclaved cellular concrete (BCA). The objectives of the present study were mainly to model phosphorus adsorption processes using Langmuir and Freundlich classical isotherms and to understand the influence of $\mathrm{pH}$ on these processes. For a complete description of the process, isotherms were determined at $\mathrm{pH}$ values of 3 and 9, and mathematical processing of experimental data was attempted based on the above mentioned models. Based on the experimental results obtained, it is observed that the removal of phosphate ions from the wastewater by adsorption processes on pumice stone and BCA is more efficient at a strongly acidic $\mathrm{pH}$, and the Freundlich thermodynamic model offers better process behavior.
\end{abstract}

Keywords: adsorption, autoclaved cellular concrete, phosphate, pumice stone, wastewater

\section{Introduction}

Surface waters contain a certain level of phosphorus in various forms, which is an important component of living organisms. Excess phosphorus contained in receiving waters leads to excessive algal growth (eutrophication). The phenomenon of eutrophication usually decreases the water quality and as a result, it can significantly increases the cost of water treatment (Archna et al 2012, Thiruvenkatachari et al 2008).

As is well known, currently, the eutrophication is one of the main problems in the monitoring of water sources in industrialized countries. Because a small amount of phosphorus can cause water contamination and accelerates the growth of algae and other aquatic plants, effluent standards for phosphorus concentration are becoming stricter. This is why wastewater needs removal of phosphate before it is discharged into emissaries. The biological treatment for phosphate removal is a popular and 


\section{INTERNATIONAL SYMPOSIUM "THE ENVIRONMENT AND THE INDUSTRY", SIMI 2018, PROCEEDINGS BOOK}

important method mainly due to reduced costs, but usually the effluent does not meet strict standards to be discharged and, as a consequence, it requires further treatment. Chemical precipitation is another approach used for phosphate removal and usually has a high removal efficiency, but produces large amounts of sludge and leads to the problem of secondary pollution. The advantage of the adsorption process towards the biological and chemical approach is that it does not present their problems (Blowes et al 2000, Yan et al 2010). Thus, developing an extremely efficient adsorbent can lead to a promising method for removing phosphate (Huichaoa et al 2011, Oguz et al 2003).

The pumice stone and autoclaved cellular concrete (BCA) are porous materials with a high specific surface area (the pore volume reaching up to $85 \%$ in the case of pumice stone) and a high silicon content (generally 60-75\% $\mathrm{SiO}_{2}$ ) which gives them excellent adsorptive properties. Moreover, these are low-cost and locally available materials (Ayoub \& Semerjian 2006, Weijie et al 2016).

According to NTPA 001/2002 and NTPA 002/2002 (Table 1), wastewater must meet certain conditions before it is discharged to the emissaries.

Table 1. Limit values for phosphorus loading of industrial and municipal wastewater

\begin{tabular}{ccc}
\hline Quality indicator & $\begin{array}{c}\text { Admissible limit values, } \\
\mathrm{mg} / \mathrm{dm}^{3}\end{array}$ & Analysis method \\
\hline Total phosphorus & $1(2)$ & SR EN 1189:1999 \\
Synthetic detergents & 0.5 & SR ISO 7825/1:1996 \\
& SR ISO 7825/2:1996 \\
\hline
\end{tabular}

According to the Technical Standard for Water Protection NTPA 002/2002, the limit values for the loading of pollutants (phosphorus) of industrial and municipal wastewater discharged into the sewerage networks of the localities and directly in the wastewater treatment plants are in accordance with Table 1.

\section{Materials and Methods}

A series of adsorption experiments were carried out in this work in order to establish the influence of some parameters such as the $\mathrm{pH}$ and phosphate concentration of the initial solution, as well as the chemical composition of the adsorbents on the adsorption efficiency. The experiments were carried out on two types of adsorbent materials namely pumice stone and BCA at two $\mathrm{pH}$ values of 3 and 9 and at a mass ratio of 1:10. The granule size of the adsorbent materials was between 0.063 and 2 $\mathrm{mm}$.

The adsorption experiments involve contacting the samples of adsorbent material for 1 hour with the phosphate solution of variable concentrations of $10,20,40,60,80$, $100 \mathrm{mg} / \mathrm{L}$, to achieve the equilibrium. After 1 hour the suspension was filtered (size filter of $0.45 \mu \mathrm{m}$ ) and the resulting solution was measured for concentration.

The resulting aqueous extract was analyzed on the X-ray spectrometer (Blank \& Eksperiandova 1998, Marguil et al 2009). The chemical composition of the adsorbent materials (Table 2 ) and subsequent analysis of samples was performed by $\mathrm{XRF}$ analysis (X-ray fluorescence). 


\section{INTERNATIONAL SYMPOSIUM "THE ENVIRONMENT AND THE INDUSTRY", SIMI 2018, PROCEEDINGS BOOK}

Table 2. Chemical composition for pumice stone and BCA, XRF analysis

\begin{tabular}{ccccccc}
\hline Composition & $\mathrm{SiO}_{2}, \%$ & $\mathrm{Al}_{2} \mathrm{O}_{3}, \%$ & $\mathrm{Fe}_{2} \mathrm{O}_{3}, \%$ & $\mathrm{CaO}, \%$ & $\mathrm{MnO}, \%$ & Others, \% \\
\hline Pumice stone & 51.26 & 14.84 & 3.16 & 28.08 & 0.099 & 2.54 \\
\hline BCA & 61.01 & 13.05 & 2.93 & 21.73 & 0.078 & 1.2 \\
\hline
\end{tabular}

The energy spectra for the two adsorbents are shown in Figure 1 and Figure 2.

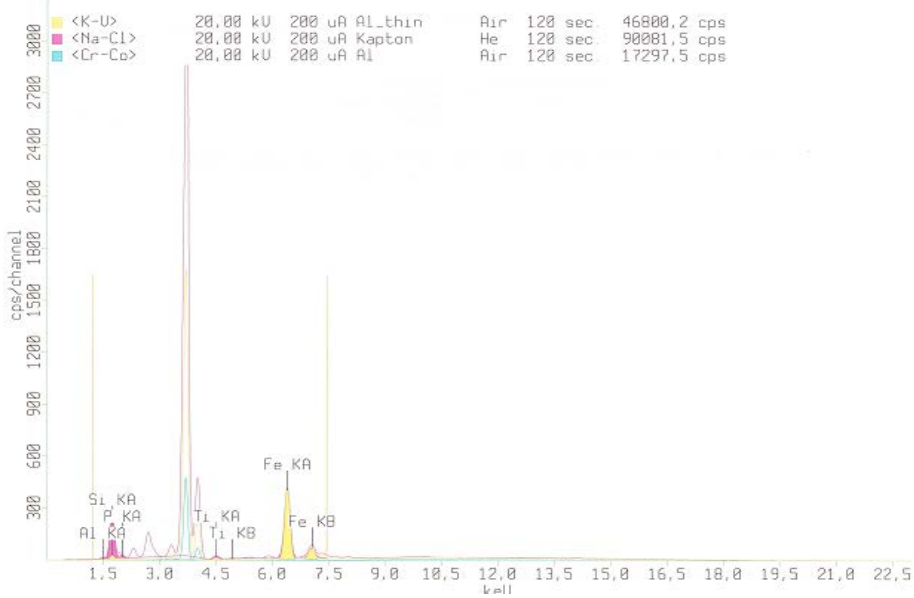

Figure 1. The energy spectrum for pumice stone
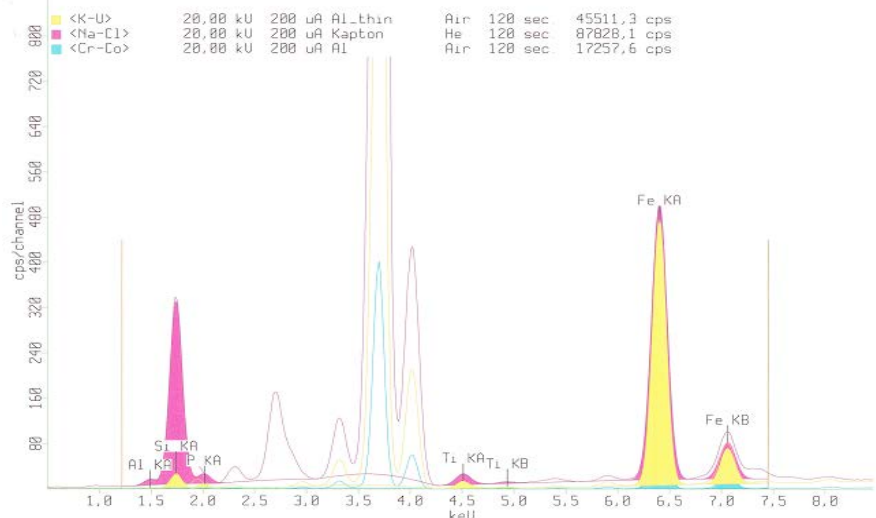

Figure 2. The energy spectrum for BCA

\section{Results and Discussion}

The equilibrium curves derived from experimental results are used to determine the degree of retention of phosphorus on the two types of adsorbent materials (pumice stone and BCA) using the Langmuir and Freundlich isotherms at a mass ratio of the adsorbent material: water of 1:10, at $\mathrm{pH} 3$ and $\mathrm{pH}$ 9. With Langmuir and Freundlich isotherms, the Langmuir and Freundlich isotherms were constructed using linear 


\section{INTERNATIONAL SYMPOSIUM "THE ENVIRONMENT AND THE INDUSTRY", SIMI 2018, PROCEEDINGS BOOK}

model regression models. Using the model parameters, computed by linear regression, the Langmuir and Freundlich isotherms were drawn (Dada et al 2012).

Based on the adsorption isotherms describing the relationship between the adsorbed phosphorus and its concentration at equilibrium in the solutions, the Langmuir and Freundlich isotherms were drawn and the maximum adsorption $\left(\mathrm{a}_{\max }\right)$ and the constant $(\mathrm{K})$ relative to the adsorption energy were calculated. The Langmuir model considers that retention results from the adsorption of the solute on an energyhomogeneous surface, and the Freundlich model starts from the hypothesis of reaching the chemical equilibrium when there is a dynamic exchange between the molecules of the adsorbed phase and the one left in the solution. The relevant parameters obtained using the Langmuir and Freundlich models are shown in Tables 3 and 4.

Table 3. Thermodynamic parameters for pumice stone

\begin{tabular}{ccccccc}
\hline & \multicolumn{3}{c}{ Langmuir } & \multicolumn{3}{c}{ Freundlich } \\
\cline { 2 - 7 } & $\begin{array}{c}\mathrm{K} \\
\left(\mathrm{mg}^{-1} \cdot \mathrm{L}\right)\end{array}$ & $\begin{array}{c}\mathrm{a}_{\max } \\
(\mathrm{mg} / \mathrm{kg})\end{array}$ & $\mathrm{R}^{2}$ & $\mathrm{~K}$ & $\mathrm{~m}$ & $\mathrm{R}^{2}$ \\
\hline 3 & 0.134 & 1006.69 & 0.9174 & 141.939 & 0.597 & 0.9755 \\
\hline 9 & 0.042 & 924.14 & 0.9204 & 67.82 & 0.594 & 0.9540 \\
\hline
\end{tabular}

Table 4. Thermodynamic parameters for BCA

\begin{tabular}{cccccccc}
\hline \multirow{2}{*}{$\mathrm{pH}$} & \multicolumn{3}{c}{ Langmuir } & \multicolumn{3}{c}{ Freundlich } \\
\cline { 2 - 7 }$\left(\mathrm{mg}^{-1} \cdot \mathrm{L}\right)$ & $\begin{array}{c}\mathrm{a}_{\max } \\
(\mathrm{mg} / \mathrm{kg})\end{array}$ & $\mathrm{R}^{2}$ & $\mathrm{~K}$ & $\mathrm{~m}$ & $\mathrm{R}^{2}$ \\
\hline 3 & 0.087 & 859.20 & 0.8271 & 88.66 & 0.6188 & 0.9304 \\
\hline 9 & 0.058 & 630.50 & 0.8209 & 68.369 & 0.5153 & 0.9047 \\
\hline
\end{tabular}

According to the quadratic value of correlation coefficients $\left(\mathrm{R}^{2}\right)$ the adsorption of phosphate was better evaluated by the Freundlich model $\left(\mathrm{R}^{2}=0.90 \div 0.97\right)$ than the Langmuir one $\left(\mathrm{R}^{2}=0.82 \div 0.92\right)$ for both of adsorbents. These results reflect the surface heterogeneity of these adsorbents in relation with the active sites and their energies.

The various phosphate anions in the solution are attracted by the positively charged areas at the surface of the adsorbent material particles in accordance with the anion exchange capacity.

Using the model parameters, computed by linear regression, the Langmuir and Freundlich isotherms were drawn (Figures 3 and 4). 


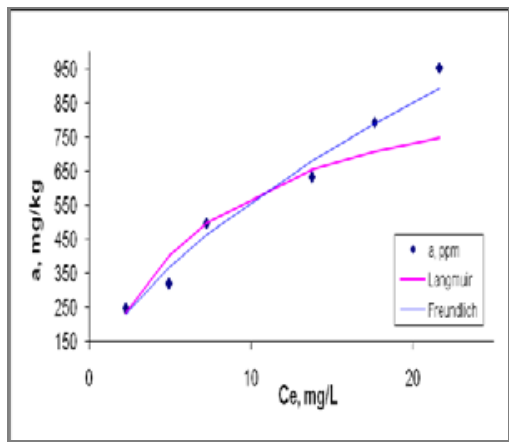

a) $\quad \mathrm{pH}=3$

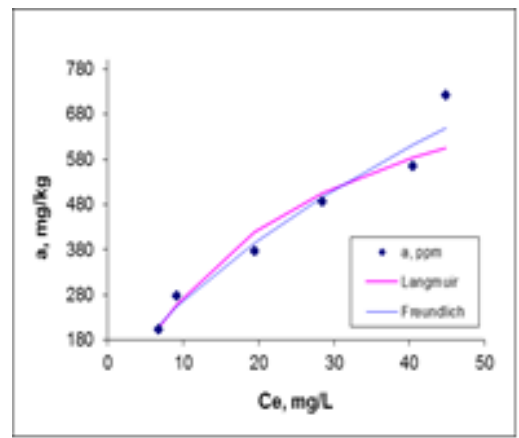

b)

Figure 3. Langmuir and Freundlich isotherms for pumice stone at $\mathrm{pH} 3$ and $\mathrm{pH} 9$

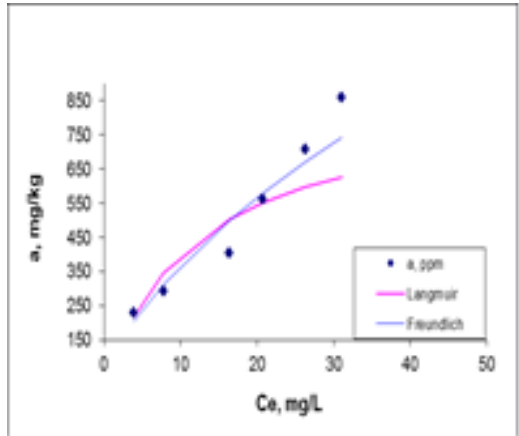

a) $\quad \mathrm{pH}=3$

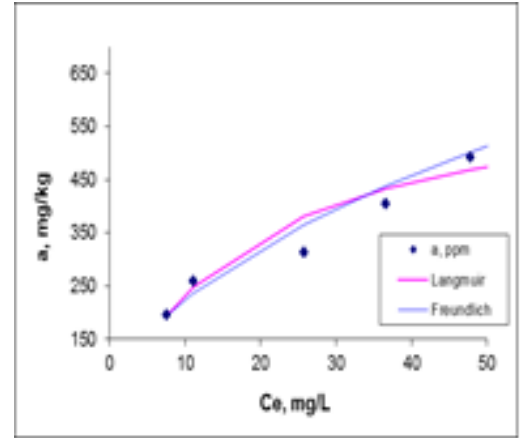

b)

$$
\mathrm{pH}=9
$$

Figure 4. Langmuir and Freundlich isotherms for BCA at $\mathrm{pH} 3$ and $\mathrm{pH} 9$

The data of the adsorption isotherms shown in these figures were fitted based on these isotherms using the smallest squares method $\left(R^{2}=0.82 \div 0.97\right)$. The isotherm graph, for the Langmuir and Freundlich model, represents the loading (the amount of phosphate adsorbed) depending on the concentration of the phosphates in the solution. The shape of the Langmuir isotherm is characterized in this case by an initial abrupt sector, practically linear, followed by a curved middle sector. The absence of the horizontal sector demonstrates the high availability of the adsorbent material for the adsorption process. This trend is specific to the chemosorption and physical adsorption phenomena where the adsorption is carried out in the monomolecular layer.

At high concentrations of the phosphate ions in the solution, the adsorbent sorption capacity is exceeded, and the isotherm is flattened. At low concentrations, the isothermal slope can become abrupt, resulting in the normal Langmuir isotherms. In the present case we have isotherms indicating pronounced adsorption. 


\section{INTERNATIONAL SYMPOSIUM "THE ENVIRONMENT AND THE INDUSTRY", SIMI 2018, PROCEEDINGS BOOK}

Figures 3 and 4 illustrate the adsorption $\mathrm{f}$ phosphorus on the pumice stone and BCA. It can be seen that the phosphorus retention equilibrium on the two types of adsorbent materials can be mathematically described by Langmuir and Freundlich thermodynamic models.

The adsorption isotherms express the specific relationship between the sorbent concentration and the amount adsorbed on its surface under the given experimental conditions. The phosphorus adsorption on the surface of the adsorbent materials is determined by both the surface load and the protonation state of the phosphorus in the crude solution. Laboratory studies on pumice stone and BCA have shown that phosphorus sorption varies with $\mathrm{pH}$ (Loganathan et al 2014). Adsorption occurs not only through adsorbent interactions with phosphate ions, but also through the physical interferences between $\mathrm{AlPO}_{4}$ and the adsorbent surface (Zhou et al 2005).

\section{Conclusions}

The results of this study show that BCA and pumice stone are effective adsorbents for the removal of phosphate ions from aqueous solutions. It has been found that the amount of the phosphate adsorbed depends on the $\mathrm{pH}$ of the solution. Thus, the removal of phosphate ions from wastewater through adsorption processes on pumice stone and BCA is more effective at a strongly acidic $\mathrm{pH}$, and the Freundlich thermodynamic model offers better process behavior.

The phosphate adsorbed on BCA and pumice stone can be used in agriculture as a fertilizer. Thus, developing an extremely efficient adsorbent can lead to a promising method for removing phosphates.

By effectively acting to remove phosphorus from domestic and industrial wastewaters and rationalizing the use of fertilizers in agriculture, the main factors driving the proliferation of aquatic vegetation can be reduced, so the secondary pollution of surface water can be also reduced.

In conclusion, equilibrium equations, in particular their parameters, can be input data for mathematical models that describe the phosphorus behavior more fully while the phosphorus adsorption process presents a complicated mechanism and can be influenced by various factors.

\section{References}

Archna, Sharma, KS \& Sobti, RC 2012, 'Nitrate Removal from Ground Water: A Review, E-Journal of Chemistry, vol. 9, no. 4, pp. 1667-1675.

Ayoub, GM \& Semerjian, L 2006, 'Low Cost Processes for the Removal of Phosphates in Water and Wastewater', International Journal of Environmental Technology and Management, vol. 6, no. 5, pp. 448 - 465.

Blank, AB \& Eksperiandova, LP 1998, 'Specimen Preparation in X-Ray Fluorescence Analysis of Materials and Natural Objects', X-Ray Spectrometry, vol. 27, pp. 147-160.

Blowes, DW, Ptacek, CJ, Benner, SG, McRae, CWT, Bennett, TA \& Puls, RW 2000, 'Treatment of inorganic contaminants using permeable reactive barriers', Journal of Contaminant Hydrology, vol. 45, pp. 123-137.

Dada, AO, Olalekan, AP \& Olatunya, AM 2012, 'Langmuir, Freundlich, Temkin and Dubinin-Radushkevich Isotherms Studies of Equilibrium Sorption of $\mathrm{Zn}^{2+}$ Unto Phosphoric Acid Modified Rice Husk', IOSR Journal of Applied Chemistry, vol. 3, no.1, pp 38-45. 


\section{INTERNATIONAL SYMPOSIUM "THE ENVIRONMENT AND THE INDUSTRY", SIMI 2018, PROCEEDINGS BOOK}

Huichaoa, G, Wenjunb, LI, Huanyinga, W, Jinghuac, ZG, Yangc, L \& Yue, Z 2011, 'A study of phosphate adsorption by different temperature treated hydrous cerium oxides', Rare Metals, vol. 30, no. 1, pp. 58.

Loganathan, P, Vigneswaran, S, Kandasamy, J \& Bolan, NS 2014, 'Removal and recovery of phosphate from water using sorption', Critical Reviews in Environmental Science and Technology, vol. 44, no. 8, pp. 847-907.

Marguil, E, Queralt, I \& Van Grieken, R 2009, 'Sample Preparation for X-Ray Fluorescence Analysis', Encyclopedia of Analytical Chemistry.

Oguz, E, Gurses, A \& Yalcin, M 2003, 'Removal of phosphate from waste waters by adsorption', Water, Air and Soil Pollution, vol. 148, pp. 279-287.

Thiruvenkatachari, R, Vigneswaran, S \& Naidu, R 2008, 'Permeable reactive barrier for groundwater remediation', Journal of Industrial and Engineering Chemistry, vol. 14, no. 2, pp. 145-156.

Weijie, L, Lixuang, Z, Yuan, K, Qiuyun, Z, Jiwen, L \& Xingmei, G 2016, 'A solid waste, crashed autoclaved aerated concrete, as a crystalline nucleus for the removal of low concentration of phosphate', Desalination and Water Treatment, vol. 57, no. 30, pp. 14169-14177.

Yan, L, Xu, Y, Yu, H, Xin, X, Wei, Q \& Du, B 2010, 'Adsorption of phosphate from aqueous solution by hydroxyl-aluminum, hydroxyl-iron and hydroxyliron-aluminium pillared bentonites', Journal of Hazardous Materials, vol. 179, pp. 244-250.

Zhou, A, Tang, H \& Wang, D 2005, 'Phosphorus adsorption on natural sediments: Modeling and effects of $\mathrm{pH}$ and sediment composition', Water Research, vol. 39, pp. 1245-1254. 